\title{
ANTIGITANISMO Y CAMBIOS EN LOS DERECHOS Y CONDICIONES ESCOLARES DE LA INFANCIA GITANA EN ESPAÑA (1970-1995)'
}

\author{
Anti-Gypsyism and changes in rights and educational \\ conditions of gypsy childhood in Spain (1970-1995)
}

\author{
MANUEL ÁNGEL RÍO RUIZ \\ Universidad de Sevilla \\ manurio@us.es
}

Cómo citar/Citation

Río Ruiz, M. A. (2018)

Antigitanismo y cambios en los derechos y condiciones escolares de la infancia gitana en España (1970-1995)

Historia y Política, 40, 179-210

doi: https://doi.org/10.18042/hp.40.07

(Recepción: 29/09/2017. Evaluación: 16/02/2018. Aceptación: 19/05/2018. Publicación: 02/11/2018)

\section{Resumen}

Este artículo estudia la historia reciente de rechazos a la infancia gitana en las escuelas estatales españolas en un momento de intentos de cambios sociales y políticos, tras siglos de sostenida exclusión educativa. Se analizan eventos sucedidos en un periodo de 35 años en el que se produjo una transformación en el tratamiento político y percepción social de la cuestión gitana. El texto se centra en la intensificación a partir de la década de 1980 tanto de la incorporación escolar de la infancia gitana como del subsecuente ciclo de protestas antigitanas. El artículo identifica, por un lado, los distintos factores que contribuyeron al aumento de la conflictividad étnica

1 Texto elaborado en el marco del Proyecto I+D «Historia de los gitanos: exclusión, estereotipos y ciudadanía (Siglos XVIII-Xx)», Ref. HAR2015-64744-P. 
en las escuelas estatales y muestra, por otro lado, el creciente fracaso de las protestas antigitanas, al desencadenar una creciente contestación social en contra de la vulneración de derechos fundamentales de la infancia.

\title{
Palabras clave
}

Gitanos; antigitanismo; escolaridad; protesta social.

\begin{abstract}
This article studies the recent history of rejection of Gypsy children in Spanish state schools during a time of significant social and politics changes and after centuries of sustained educational exclusion. The analysis deals with events occurring in a thirty-five years period during which there was a transformation in the political treatment and social perception of the gypsy question. The article focuses on the increasing numbers of Gypsy children joining the school system from the 1980s onwards and the subsequent series of anti-Gypsy protests. The article identifies, on the one hand, the various factors that contributed to the increase in ethnic conflict in state schools; it shows, on the other, the increasing failure of anti-Gypsy protest, as it unleashed a social reaction against the violation of fundamental child rights.
\end{abstract}

\section{Keywords}

Roma; anti-Gypsyism; schooling; social protest. 


\section{SUMARIO}

I. INTRODUCCIÓN: 1. Marco teórico para explicar la movilización antigitana en España. 2. Metodología: el «análisis de eventos» antigitanos a través de la prensa. II. MARGINAL Y MARGINADORA: LA ACCIÓN ESTATAL EN MATERIA DE EDUCACIÓN GITANA. III. EXCLUSIÓN EDUCATIVA DURANTE EL FRANQUISMO Y LA TRANSICIÓN. IV. LA «AVALANCHA»: PROTESTAS Y RESISTENCIAS A LA INCLUSIÓN ÉTNICA EN UN MARCO POLÍTICO CAMBIANTE. V. LA CONSOLIDACIÓN DE LA PRESENCIA GITANA EN LAS ESCUELAS ESTATALES. VI. CONCLUSIONES. BiblIOGRAFÍA.

\section{INTRODUCCIÓN}

En mayo de 1970 «corrieron rumores» de que «iban a ser declarados como subnormales» los menores de un "poblado gitano» cercano a una barriada zaragozana donde se acababa de construir una nueva escuela pública en un contexto de escasez generalizada de plazas escolares. La iniciativa partiría de "círculos oficiales del magisterio» y habría sido trasladada a la Delegación de Educación. Sus responsables, aunque desmintieron dichos rumores, admitieron la realización específica a los niños gitanos de unas previas "pruebas de nivel» que no superaron estos. También subrayaron el amplio rechazo que el intento de escolarización de aquellos niños venía concitando entre la mayoría del vecindario. La prensa local del tardofranquismo, que confirmó y criticó tibiamente el boicot vecinal, se declaraba dispuesta a admitir una salida al conflicto que pasara por una nueva escuela donde pudieran educarse separadamente los menores rechazados ${ }^{2}$.

Quince años después, en enero de 1985, los antidisturbios cargaban varios días contra centenares de madres mientras bloqueaban el acceso de una treintena de menores gitanos a un colegio público, el Severo Ochoa, del barrio de Vicálvaro (Madrid) $)^{3}$. En un primer momento, antes del estallido etnicista, estaba previsto que los nińos rechazados se concentraran en un aula diferenciada del centro. Y solo mientras durara la reparación de la «escuela gitana» de la cual provenían, ubicada en un asentamiento chabolista cercano. Sin

2 «Los payos no aceptan que nuestros hijos estudien con los suyos», Heraldo de Aragón, 26-05-1970.

3 «Los 35 niños gitanos de Vicálvaro entraron a clase protegidos por la policía», El País, edición de Madrid, 9-1-1985, p. 17. 
embargo, a raíz de la litigación supracomunitaria que concitó aquel mediático boicot etnicista de los ochenta, avanzaría el derecho a la educación no segregada de menores gitanos. Y esto tanto en el Severo Ochoa, donde al final llegaron para quedarse más niños gitanos de los provisionalmente contemplados, como en muchos otros colegios madrileńos y estatales.

A pesar de los costes crecientes y fracasos recurrentes que irán cosechando las protestas populares para preservar la exclusión gitana de las escuelas estatales, en septiembre de 1991 centenares de manifestantes impidieron el regreso de unos pocos niños gitanos a las aulas del pueblo de Mancha Real, en Jaén. En el curso de violentas manifestaciones antigitanas, sus familias se habían visto meses antes expulsadas del pueblo ${ }^{4}$. En estos años las asociaciones gitanas, acompañadas y apoyadas en Mancha Real por autoridades como el defensor del Pueblo y el delegado del Gobierno, convirtieron la vuelta de los nińos gitanos a clase en una escenificación cabalmente articulada en la cual la protesta por el agravio específico sufrido se articuló con una reivindicación global de los derechos fundamentales de la minoría. Derechos que no podrían seguir conculcándose, como acaba de ocurrir en Mancha Real y había sucedido pocos años antes en otros pueblos de la provincia jiennense donde también fueron expulsadas familias gitanas. Por los sucesos etnicistas del colegio de Mancha Real, en enero de 1995, la Audiencia Provincial de Jaén condenaba de manera pionera en España a decenas de (madres) participantes a cuantiosas multas por conducta agresiva, racista y xenófoba ${ }^{5}$.

Este tipo de manifestaciones de antigitanismo ${ }^{6}$ son escasamente conocidas y sobre todo han sido escasamente analizadas. Este trabajo se sumaría a esfuerzos interdisciplinares recientes para completar esas injustificadas lagunas 7 . Más si cabe en unas décadas, como las abordadas en estas páginas, de intensos cambios en la distribución interétnica de recursos y oportunidades

4 Río (2003): 60-70.

5 «Cuatro gitanos de Mancha Real, solos en las aulas en el primer día de clases», El Pais, 17-9-1991.

6 La Comisión Europea contra el Racismo y la Intolerancia (ECRI), en su Recomendación de política general núm. 13, adoptada el 24 de junio de 2011, conceptualiza el «antigitanismo» como una forma de racismo persistente, violenta y banalizada basada en el origen cultural de las personas romaníes, que reúne raíces sociales pero sigue reproduciéndose institucionalmente.

7 Como apunta Sierra (2018: 359), «paradójicamente de la historia del antigitanismo en Espańa conocemos bastante mejor su principio y sólo puntualmente algunos episodios recientes". 
sociales, en las maneras cada vez más plurales de vivir la identidad gitana, así como en las relaciones y conflictos vecinales con elementos etnicistas.

En lo que concierne al campo educativo, durante los veinticinco ańos que median entre el primero y último de los tres casos citados cambiaron las condiciones escolares y el tratamiento institucional reservado a la infancia gitana. A su vez, cambiaron las condiciones de posibilidad de los boicots escolares y los marcos de significados desplegados durante las movilizaciones para preservar o recomponer la exclusión gitana de los colegios públicos. Finalmente, cambiaron las reacciones frente a estos sucesos por parte de funcionarios y poderes públicos, medios de comunicación y sectores del movimiento asociativo gitano.

Este artículo reconstruye esa historia reciente de revueltas contra la tardía y asimétrica incorporación de la infancia gitana a las escuelas españolas. Incorporación casi siempre restringida a centros públicos situados en barriadas obreras que también asistieron a la multiplicación de programas de realojo durante estos ańos. El trabajo identifica los distintos efectos conflictivos de la escolarización de menores gitanos en paralelo al cambio en las intervenciones y prioridades de los poderes públicos en materia de escolaridad gitana. Revela la progresiva configuración de un nuevo orden de legitimidades en cuanto al trato escolar dispensable a la infancia gitana. Ese nuevo orden de legitimidades será construido también en el marco de los propios conflictos donde el derecho a la educación de la minoría era violado. El análisis se concentra en acciones discriminatorias y movilizaciones acaecidas en escuelas públicas hasta mitad de los noventa. Aunque se revelan algunos pocos casos en centros concertados de los noventa, apenas se aborda la sucesión y trama de situaciones discriminatorias que, pese a los avances en el sistema público, han ido conformando en las últimas décadas la extendida exclusión gitana de la red escolar concertada ${ }^{8}$.

\section{MARCO TEÓRICO PARA EXPLICAR LA MOVILIZACIÓN ANTIGITANA EN ESPAÑA}

El análisis e interpretación de las dinámicas que concurren en los episodios de etnicismo escolar está apoyado y se construye sobre la base de distintas aportaciones teóricas sobre etnicidad, etnicismo y conflicto étnico unificadas sobre

8 Tampoco se aborda la nueva formación de «escuelas-guetos» en algunos colegios públicos de las periferias urbanas evitados ya sistemáticamente por la población no gitana. 
todo en su rechazo a las concepciones primordialistas y ahistóricas de la etnicidad que proyectan imágenes estáticas del antagonismo étnico? ${ }^{9}$. Del enfoque primordialista se destacará su incapacidad para explicar si los antagonismos y conflictos étnicos remiten cuando se evaporan las desigualdades interétnicas, o si en cambio persisten o intensifican cuando el acceso a ciertos recursos y oportunidades sociales es, desde el punto de vista étnico, más paritario.

La señalada, en cambio, es la cuestión que tratará de responder la teoría de la competición étnica ${ }^{10}$. Este enfoque ha sido criticado ${ }^{11}$ por utilizar medidas indirectas de competición — variaciones en la composición étnica de un mercado laboral, por ejemplo- que se identifican bajo la lógica del modelo con variaciones en los niveles de competición entre los grupos allí donde se dan conflictos étnicos. Pese a la crítica a la circularidad en la que incurriría la teoría de la competición étnica, hay dos hipótesis de este modelo que han vertebrado la construcción del objeto y la explicación de los conflictos antigitanos en la España reciente. En primer lugar, este artículo apoya la hipótesis de que sistemas de redistribución interétnica de los recursos, cuando suponen un incremento de los niveles de interdependencia interétnica, promueven la politización de las fronteras, de la acción colectiva, y de la solidaridad étnica ${ }^{12}$.

En segundo lugar, este artículo apoya la hipótesis sobre el papel clave que juegan las agencias estatales como actores estructurantes de las divisorias y tensiones interétnicas, resultando el Estado a su vez principal foco de expresión de demandas y agravios interétnicos. En esta línea, un estudio ${ }^{13}$ explicaba la solidaridad étnica en las sociedades modernas a partir del paradójico papel de las políticas públicas universalistas como promotoras de identificaciones en términos étnicos. Otro trabajo ${ }^{14}$ reveló "procesos de etnogénesis» a través de dinámicas competitivas desencadenadas entre grupos aspirantes a alcanzar similares ventajas y grados de reconocimiento estatal ${ }^{15}$.

9 Un trabajo de Río (2002) integra las críticas a la visión primordialista y resume explicaciones de la etnicidad alternativas a este enfoque. En dicho texto se define la etnicidad como una forma básica de asociación e identidad social en base a rasgos culturales compartidos, cuya plasticidad es limitada, pero que pueden y suelen utilizarse como recursos políticos.

10 Nagel (1995) y Nagel y Olzak (1997).

11 Díez (1994): 22.

12 Olzak (1992) y Wilkes y Okamoto (2002).

13 Nielsen (1985).

14 Roosens (1989).

15 Parte de la bibliografía sustantiva sobre el papel del Estado en procesos de etnogénesis fue resumida por Río (2002: 88-95). 
En el marco teórico explicitado destacan los trabajos de sociología histórica de la protesta racial en Estados Unidos a cargo de Olzak con otras autoras $^{16}$. En concreto, al analizar la convulsa evolución de las «relaciones raciales» en los sesenta muestran cómo «particularmente en las primeras etapas de contacto interracial y allí donde la segregación escolar era más severa» ${ }^{17}$, las escuelas federales recién obligadas a ejecutar medidas desegregativas (desegregation busing) se convirtieron en escenarios recurrentes de resistencias civiles a la inclusión racial. Las conclusiones de estas autoras, trasladables como veremos al ciclo de protestas antigitanas en las escuelas españolas, fueron que:

Los cambios en los niveles de contacto y exposición interracial en las escuelas afectaron a las tasas de acción colectiva étnica [...]. En particular, la ruptura de los patrones de segregación en las escuelas que antes eran formalmente blancas expandieron las disputas locales por el acceso a las oportunidades, y la distribución de recursos educativos [...]. Estos conflictos invocaban, tanto a miedos de la población blanca al contacto interracial, como a la percepción de que la competición racial por recursos escasos se incrementaría aún más ${ }^{18}$.

El peso que ejerce el pasado segregativo en el conflicto étnico ya había sido abordado por la sociología neoweberiana del conflicto social. Para Parkin $^{19}$, los grupos objeto de exclusión son los que han sufrido históricamente los perjuicios de un estatus marginal. Aunque con el paso del tiempo la situación de desventaja en el terreno político y legal de estos grupos pueda formalmente desaparecer, las desventajas heredadas continuarán marcándolos como víctimas de la exclusión. Políticas anteriores discriminatorias a cargo del Estado, incluso cuando se ven sustituidas por tratamientos institucionales más igualitarios para los colectivos racializados, conservarán poderosos efectos sociales al haber naturalizado la exclusión. Al haber conformado expectativas segregativas entre las poblaciones, también en el sistema escolar.

El artículo mostrará cómo las nociones de Parkin son claves para explicar la historia reciente de las relaciones y conflictos con la comunidad gitana en España. Se sostiene que la comunidad gitana, en otras épocas privada de facto de derechos civiles y políticos, acabará convirtiéndose en el «objetivo

16 Olzak (1992); Olzak et al. (1994); Olzak et al. (1996), y Olzak y Shanahan (2003).

17 Olzak et al. (1996): 592.

18 Olzak et al. (1994): 232. Antes, Lieske (1978: 87) también señaló que «la violencia racial en la escuela y la comunidad es directamente exacerbada por la extensión en la cual las escuelas son racialmente desegregadas».

19 Parkin (1984): 136-139. 
natural» de las acciones excluyentes de la población mayoritaria. Esto sucederá especialmente cuando los poderes públicos retiran el apoyo sistemático que antes prestaban a la segregación escolar de los gitanos, como sucedió en muchos colegios públicos espańoles antes inaccesibles para los gitanos.

La multiplicación desde los ochenta de niños gitanos en escuelas estatales y la proliferación de protestas civiles contra la inclusión étnica en ellas representan, por tanto, dos fenómenos interdependientes. Puede hablarse para estos ańos de un ciclo de conflicto étnico. Por un lado, la quiebra de los límites étnicos prevalecientes en muchos colegios estatales precipitó, sobre todo a lo largo de los ochenta, decenas de protestas civiles contra la presencia de alumnado gitano. En ellas se desplegaron habituales prejuicios contra los gitanos y nuevos agravios sociales, como el que incidía en el muy desigual reparto entre los barrios y colegios de distintas clases sociales del nuevo alumnado. Sin embargo, al violarse en ellos derechos cada vez más protegidos y objetivados institucionalmente por las propias leyes educativas, los episodios de etnicismo escolar serán los más costosos de sostener. Los que más fracasos cosechan a medida que avanza la democracia. De hecho, nada más saltar a la luz pública, estos casos desencadenarán multisectoriales reacciones y litigaciones supralocales que contribuirán a la problematización y denuncia social de las condiciones de postergación educativa que seguiría atravesando buena parte de la infancia gitana en España.

De esta manera, las revueltas contra la inclusión escolar acabarán, en cambio, estructurando oportunidades y dinámicas de reivindicación proactiva para la consolidación y el avance de derechos ante la escuela y otros ámbitos. Esta misma dinámica fue explicada por $\mathrm{McAdam}^{20}$ en su trascendental estudio de la protesta racial y de las estrategias del movimiento por los derechos civiles, el cual convertía los escenarios más probables de reacciones racistas en lugares de denuncias más amplias sobre la desigualdad histórica de trato racial.

Otros estudios ${ }^{21}$ han también mostrado cómo los episodios de discriminación galvanizan a las comunidades discriminadas activando sus lazos, redes y estrategias reivindicativas. En el caso de los gitanos, aunque se necesita todavía de más información para más tipos de conflictos, la reconstrucción de episodios de etnicismo escolar realizada permite al menos plantear — entre otras cuestiones y objetivos centrales más desarrollados en el texto- la hipótesis provisional de un progresivo incremento de la influencia de las asociaciones gitanas en la denuncia, amplificación y litigación de casos de discriminación.

20 McAdam (1999).

21 Olzak (1992): 182-186, y Wilkes y Okamoto (2002). 


\section{METODOLOGÍA: EL «ANÁLISIS DE EVENTOS» ANTIGITANOS A TRAVÉS DE LA PRENSA}

Metodológicamente el trabajo se sustenta en una estrategia de «análisis de eventos» a través de la explotación (principalmente) de prensa local y nacional del tardofranquismo, la transición y la democracia ${ }^{22}$. Aunque se revisó el diario El País, desde sus orígenes e incluyendo ediciones regionales, la diversificación de fuentes que enriquecen y robustecen el análisis a lo largo del periodo estudiado ha sido posible gracias a los archivos de noticias de gitanos en prensa local y nacional que desde 1967 reúne el Centro de Documentación de la ahora Fundación Secretariado General Gitano. Muchos de los casos hallados reunieron varios episodios y fueron reportados en diversos periódicos a la vez. Ello permitió aumentar la fiabilidad de las fuentes documentales mediante la triangulación de la información sobre los casos, sin depender de una única fuente. Las noticias de movilizaciones vecinales en las escuelas, pero también los casos de discriminación oficial y las crecientes denuncias ante estas situaciones, han conformado las unidades de análisis. Se han analizado también editoriales al hilo de estos casos en prensa nacional y en publicaciones gitanas especializadas, como Nevipens Romaní, fundada en 1986, o el boletín Gitanos en la prensa. También se ha recurrido a documentos legislativos en materia de inclusión escolar, así como a estudios e informes que dan cuenta de los cambios en las condiciones escolares de la población gitana entre el tardofranquismo y mitad de los noventa.

Historiadores que evalúan la fiabilidad de la prensa como fuente de datos sobre conflictos subrayan que al explotarla «tenemos más riesgos de información insuficiente que de información falsa» ${ }^{23}$. No obstante, como plantean las teorías críticas de la producción de las noticias, los periodistas y sus editores no sostienen un espejo frente a los hechos que reportan ${ }^{24}$. Al contrario, atribuyen motivaciones a los mismos. Configuran el sentido de estos, fundamentalmente mediante el énfasis de ciertos aspectos y el silenciamiento de otros. En

22 Véase Olzak (1989) para una explicación de las exigencias y características del «análisis de eventos» mediante registros históricos. Véase Río (2008: 62-67 y 74-79) para una evaluación de las ventajas y precauciones necesarias al explotar periódicos en ausencia de otros registros sistemáticos y alternativos de datos sobre conflictos dispersos en el espacio y tiempo. Ausencia que se da a la hora de estudiar acciones colectivas antigitanas a lo largo de la democracia.

23 Franzosi (1987): 7.

24 Véase Río (2008: 67-74) para un resumen de estas teorías críticas sobre la producción de noticias. 
este trabajo se recurrió a la prensa sobre todo para identificar de manera sistemática a lo largo del tiempo cierto tipo de datos fácticos sobre los conflictos escolares, como la localización y el tipo de participación diferenciada en ellos, los antecedentes y detonantes de las movilizaciones, las tácticas empleadas o sus secuencias y saldos. No obstante, puntualmente se han analizado algunos sesgos inherentes a las noticias de etnicismo escolar producidas en distintas épocas. Esta opción analítica se justifica también porque la cobertura y tratamiento mediático de algunos de los casos de etnicismo escolar recopilados condicionó las acciones y reivindicaciones de los distintos actores involucrados en ellos.

\section{MARGINAL Y MARGINADORA: LA ACCIÓN ESTATAL EN MATERIA DE EDUCACIÓN GITANA}

A diferencia de otros países desigualmente urbanizados e industrializados, pero que desarrollaron sistemas escolares de masas desde principios del siglo XIX, en Espańa la incorporación escolar de la infancia de clases populares presenta, aún con variaciones regionales, un significativo retraso y muchas desviaciones con respecto a otras sociedades europeas ${ }^{25}$. En el caso de la comunidad gitana española, su exclusión de la escolaridad se mantuvo para la mayor parte de las nuevas generaciones hasta entrada la década de los ochenta del siglo $\mathrm{xx}$.

Las experiencias anteriores de socialización escolar de menores gitanos pueden calificarse de puntuales; pero no de anecdóticas, si tenemos en cuenta que durante las mismas se reprodujeron las lógicas punitivas, estigmatizadoras y de desigualdad de trato que han configurado históricamente el tratamiento estatal de la llamada "cuestión gitana ${ }^{26}$. Así, entre los siglos XVII y XVIII, la mirada del Estado hacia la infancia gitana mantuvo un propósito y una voluntad más «resocializadora» que propiamente educativa. Lo dictado en materia de infancia gitana reproduce las tensiones y ambivalencias históricas del Estado hacia el pueblo gitano, entre el asimilacionismo y el etnocidio ${ }^{27}$. Al menos desde 1673 diferentes proyectos manifestaron una concepción de los menores como figuras predelictivas que reproducirían - de criarse en sus comunidades «poco cristianas»— estados de «ociosidad e infamia» ${ }^{28}$. En

\footnotetext{
Archer (1979).

Gómez-Alfaro (2009); Gómez-Urdáńez (2017), y Río (2017).

San Román (1997) y Vázquez (2009): 80-85.

«Informe Campomanes y Valiente», de 1778, citado por Leblon (1993): 62.
} 
correspondencia, se llegaron a dictar medidas de internamiento de los menores gitanos, desde que dejaban de ser lactantes hasta que, entre los doce y catorce años, pasaban a ser considerados útiles para trabajar en obras estatales, o con artesanos y propietarios agrícolas ${ }^{29}$.

Hay paralelismos entre la secuencia de planes contra el conjunto de la población gitana (como las distintas redadas) y la elaboración de planes específicamente dirigidos a la infancia gitana. Ahora bien, salvo en el caso de hijos de madres y padres recluidos, el alcance de estos proyectos fue muy limitado. Fracasaron por diversos motivos. El principal, la resistencia de las familias gitanas a la separación. Otro motivo fue la renuencia de las autoridades locales borbónicas a la creación de las «juntas de caridad y escolarización» que se encargarían de niñas y niños gitanos, así como las carencias de medios estatales para las infraestructuras de internamiento. Jugó también un papel importante el rechazo de los no gitanos a mezclarse con los gitanos, incluyendo la negativa de muchos maestros artesanos a admitir gitanos bajo su tutel ${ }^{30}$. En 1783 se dictó una prágmática asimilacionista que recogía, entre otras regulaciones, varios capítulos dedicados a la infancia gitana ${ }^{31}$. Alcaldes, corregidores y otras autoridades locales desatendieron la mayoría de las veces las medidas de asimilación contempladas en aquella pragmática que llegaba tras los intentos de extinción de ańos antes ${ }^{32}$. Hubo excepciones que se afanaron en cumplirla, como la del ministro del Crimen de la Real Audiencia de Barcelona, Francisco de Zamora. Este acogió e impuso también credo y oficio a cientos de menores gitanos y gitanas en Cataluña. En una carta a Floridablanca, dos años después de la pragmática que estaba fracasando en todo el país, Zamora relataba las dificultades para ampliar su obra debido al rechazo de muchos maestros artesanos a acoger a niños gitanos. El escrito describía también sus éxitos, señalando especialmente a las «muchachas gitanas que antes no sabían más que bailar y cantar canciones indecentes, y ya han aprendido la doctrina cristiana y las obligaciones de madre de familia ${ }^{33}$.

Más tarde, en el xix y buena parte del xx, las ideologías racistas biologicistas permearon incluso los muy localizados esfuerzos de escolarización de

\footnotetext{
Gomez-Alfaro (1991) y Salinas (2009).

Salinas (2009): 169.

Gómez-Urdáńez (2015).

Gómez-Urdáñez (2017).

33 «Memoria de los géneros trabajados por algunas hijas de los antes llamados gitanos que se hallan establecidos en el cuartel quinto de esta ciudad de Barcelona», carta de 23-11-1785 de Francisco de Zamora Aguilar a Floridablanca, cit. en Gómez-Urdáñez (2015).
} 
gitanos que se producen en estos años, como el proyecto del padre Manjón en las Escuelas del Ave María, prolongado hasta 1930. A la vez que los escolarizaba, este religioso concebía a los gitanos como pueblo incapaz de civilizarse pese al contacto con «pueblos cultos». Como «raza», su degeneración sería hereditaria y se extendería a la parte física, intelectual y moral. Más exactamente, los trataba como «mendigos de raza» dominados por la holgazanería, la astucia, el engaño y la impudicia ${ }^{34}$.

\section{EXCLUSIÓN EDUCATIVA DURANTE EL FRANQUISMO Y LA TRANSICIÓN}

En 1971 se estimó en menos del 5\% la población gitana en edad escolar en centros oficiales ${ }^{35}$. En un primer momento, pese a su masiva emigración a las ciudades, la misma quedó incluso al margen de las obras del Patronato Escolar de Suburbios implantado en 1943 para la construcción y sostenimiento de precarias escuelas ante lo que el $\mathrm{BOE}^{36}$ denominaba «expansión urbana»; en realidad, una multiplicación incesante del chabolismo-barraquismo, masivo entre la comunidad gitana de entonces ${ }^{37}$. En política educativa, de hecho, las administraciones reprodujeron las desigualdades de trato y asimetrías etnicistas que ya se dieron en el reparto de vivienda entre chabolistas no gitanos y gitanos ${ }^{38}$.

El trabajo de campo de San Román en poblados chabolistas madrileños del tardofranquismo —ocupados en sus orígenes por gitanos y no gitanosreveló que los nuevos colegios públicos que se construían en barrios cercanos a los poblados chabolistas resultaban «inaccesibles para los gitanos». En un contexto de «escasez de plazas escolares para todos», en las nuevas escuelas cercanas a los núcleos chabolistas tenían "preferencia payos sobre gitanos" chabolistas. Para los últimos, concluye San Román, las nuevas escuelas resultaban «inaccesibles»"

A partir de los sesenta, en los cada vez más extensos y segregados poblados chabolistas gitanos aumentaron las actividades de entidades vinculadas a

34 Manjón (1948): 6-31, y Abajo (2010).

35 Instituto de Sociología Aplicada (1982): 26, y Fernández-Enguita (1999): 180.

36 Orden de creación del Patronato Escolar de los Suburbios de 4 de agosto de 1942 (BOE, 26 de febrero 1943).

37 Río (2014): 39-40.

38 San Román (1997): 218.

39 San Román (1980): 185. 
la iglesia católica. La acción educativa de estas entidades fue limitada: cosechó fracasos generalizados en términos de resultados y sobre todo mantuvo y naturalizó durante décadas la segregación étnica ante la escuela, contribuyendo con ello a dificultar la posterior aceptación vecinal en colegios públicos de los menores gitanos procedentes de estos centros segregados. Lograron incrementar el porcentaje de niños escolarizados, pero rara vez sirvieron a su objetivo de adaptar al alumnado gitano para cruzar a un sistema educativo mayoritario. Lo que encontrábamos eran altas tasas de desescolarización incluso en los barrios con escuelas, altos niveles de absentismo, a profesores no especialistas y a niños hacinados sin distinción por edades ${ }^{40}$. Pese a todo ello estas escuelas reproductoras de la exclusión educativa acabaron obteniendo reconocimiento ministerial en julio de 1978, encargándose los ayuntamientos de financiarlas y la Iglesia católica de seguir gestionándolas ${ }^{41}$. En 1978 la población gitana escolarizada no llegaba todavía al $40 \%$, prevaleciendo la segregación en escuelas-puente entre los escolarizados ${ }^{42}$.

¿Y en el caso del alumnado que, pese a todo, trató de acceder en aquella época a escuelas oficiales? Para estos años, y sobre todo si la denuncia provenía de círculos eclesiásticos, la prensa local ya podía integrar casos reveladores de desigualdad de trato escolar reproducido a bajo coste político. En 1974 un medio vigués denunciaba que «nuevamente» el Apostolado-Secretariado Gitano de la ciudad no encontraba plazas escolares disponibles para nińos gitanos a quienes (al menos en esta ciudad) trataba de matricular en colegios públicos ${ }^{43}$.

Desde mediados de los setenta, una vez irrumpen nuevos medios durante la Transición, crece la huella en la prensa de casos de discriminación oficial. Un caso llamativo se dio en 1980 en los campamentos veraniegos madrileños organizados por el nuevo gobierno municipal de izquierdas. La presencia de una veintena de nińos gitanos procedentes de poblados de la zona sur concitó el rechazo y abandono "de los responsables del campamento", así como de un amplio sector de padres de los otros nińos. El bajo coste político de la discriminación de los niños gitanos en esos años se percibe a través de las declaraciones de una funcionaria y política cuya valoración naturalizaba la segregación:

La Inspectora de Educación y edil de UCD, Ana María García de Armendáriz, culpó al ayuntamiento por su improvisación, y por no haber hecho una

\footnotetext{
40 San Román (1980): 185-188; Garrido y Torres (1986), y Salinas (2009): 175.

41 Vieira Ferreira (1999).

42 Instituto de Sociología Aplicada (1990): 126.

43 «Discriminación hacia los gitanos», El Pueblo Gallego, 27-09-1974.
} 
«selección adecuada» de los niños, puesto que al ser actividades para el intercambio cultural, «no todos los niños están preparados para ellas». Señaló que las normas que regían en las colonias debían exigir unos patrones de conducta normales y que, para aquellos que no los cumplieran, se debían buscar centros especiales ${ }^{44}$.

Las élites profesionales, aunque se posicionaban crecientemente en defensa de la educación de la infancia gitana, apelaban a la segregación escolar como fórmula educativa dispensable a la minoría. De hecho, la escuela reservada a los gitanos se concebía como un necesario dispositivo asimilador y resocializador, en lugar de como un espacio de nivelación de oportunidades y promoción social. Las representaciones dominantes en los setenta sobre la escolaridad dispensable a los gitanos admiten, incluso, paralelismos con las fórmulas ampliamente ensayadas en otros países de escuelas segregadas por clase social, degradadas académicamente, así como principalmente enfocadas a la moralización y socialización anticipatoria de la clase obrera en la disciplina fabril ${ }^{45}$. En los años setenta, la escolarización de los gitanos era representada por las élites como un mecanismo necesario de asimilación a distancia para forjar buenas costumbres en naturalezas infantiles poco disciplinadas a las cuales debía extraerse de las influencias del medio familiar. En 1970 un editorial del Diario Femenino —escrito a raíz del caso de discriminación citado en una barriada de Zaragoza - reclamaba mejorar las condiciones educativas de los gitanos aún sin cuestionar la segregación escolar que reclamaba el vecindario no gitano: «No vamos a negar que sean poco disciplinados y vayan sucios [...]. Estamos dispuestos a que no sean integrados en el nuevo centro; pero no a que la sencilla escuela del poblado gitano no desaparezca. Hay que conseguir otra donde estos chicos gitanos puedan formarse. Creemos que no es pedir demasiado» ${ }^{46}$.

Las denuncias por casos de discriminación vecinal u oficial eran tibias. Aumentaban las voces reclamando soluciones al abandono educativo de la población gitana. Pero la segregación —la ausencia de socialización interétnica en un espacio clave como las aulas — apenas se cuestionaba en estos ańos. El de 1978 se cita como fundamental para el avance de los derechos en democracia de la población gitana, aunque se olvidan algunos retrocesos. Por un lado, tras una pionera y gran manifestación gitana el 7 de junio en la Puerta del $\mathrm{Sol}^{47}$, el Congreso suprimía una semana más tarde los artículos

\footnotetext{
44 «Niños gitanos excluidos de un campamente veraniego», El País, edición de Madrid, 13-7-1980.

45 Fernández-Enguita (1990).

46 «Editorial”, Diario femenino, 28-05-1970.

47 «Protesta gitana”, El Pais, 7-6-1978, p. 23.
} 
discriminatorios que subsistían en los reglamentos de los cuerpos policiales ${ }^{48}$. Por otro lado, en cambio, un mes más tarde se reconocían oficialmente en España las escuelas segregadas para gitanos ${ }^{49}$.

Una iba a construirse en Burgos. Este caso revelará nuevamente la vigencia axiológica y la naturalización de la segregación educativa de los gitanos. Presionado por "protestas del vecindario cercano», el Ayuntamiento burgalés paralizó «la construcción de la escuela para nińos gitanos». Varias asociaciones gitanas de la época ya denunciaron aquella discriminación, de la cual también se hizo eco el principal periódico progresista de la época. Finalmente, tras las denuncias y reacciones supralocales que se produjeron, el Ayuntamiento regresó a su plan inicial frenado por protestas del vecindario y reinició la obra de la escuela gitana ${ }^{50}$. Lo llamativo del caso es que, a diferencia de lo que sucedería pocos años después, la fórmula segregativa que había elegido el Ayuntamiento no fue cuestionada, ni siquiera por quienes contribuyeron a la denuncia, amplificación y litigación supracomunitaria del conflicto. No denunció la formula segregativa elegida por el Ayuntamiento la prensa progresista de entonces. Tampoco lo hicieron las asociaciones gitanas. Actores que empezaban a movilizarse incipientemente contra actuaciones «discriminatorias», «arbitrarias» $\mathrm{y}$ «racistas» "después de siglos de discriminación $»^{51}$.

\section{LA «AVALANCHA»: PROTESTAS Y RESISTENCIAS A LA INCLUSIÓN ÉTNICA EN UN MARCO POLÍTICO CAMBIANTE}

El relato histórico emprendido para recuperar la memoria de los movimientos vecinales y luchas contra la discriminación urbana en España ${ }^{52}$ desdeña el fenómeno de las movilizaciones antigitanas en esos mismos barrios. También durante la Transición, pero especialmente durante la década de los

48 Desde su promulgación el 14 de mayo de 1943 hasta su derogación en 1978 a instancias de las Cortes, los arts. 4 y 5 del Reglamento de la Guardia Civil permitían «vigilar escrupulosamente» los asentamientos, «movimientos» $\mathrm{y}$ «modo de vivir» de la población gitana, tratada como una categoría predelictiva relegada al furgón de cola de las políticas sociales. La supresión de los artículos, tras una histórica intervención del diputado gitano Ramírez Heredia, en BOE, 107, de 12 de junio de 1978, p. 243.

49 Salinas (2009).

50 «La coordinadora de asociaciones gitanas repudia la actuación del Ayuntamiento de Burgos», El Pais, 28-05-1978, p. 26.

51 Ibid.

52 Pérez y Sánchez (2009). 
ochenta y principios de los noventa, muchas de aquellas barriadas obreras abrazaron liderazgos, solidaridades y protestas etnicistas contra los tardíos realojos de familias gitanas chabolistas, oponiéndose frecuentemente también a la escolarización de niños gitanos ${ }^{53}$.

Estas movilizaciones estaban vinculadas a la multiplicación de nuevas interdependencias competitivas entre gitanos y no gitanos, como las que suponen variaciones del precio de las viviendas en función de la composición étnica de los barrios ${ }^{54}$. Los marcos de significados desplegados durante estas protestas revelan el peso de estas interdependencias competitivas. López-Varas y Fresnillo ${ }^{55}$ realizaron un estudio cualitativo en barrios del sur madrileńo, escenario de conflictos antigitanos. El estudio mostró que las representaciones sociales focalizadas en la población gitana se sustentaban, intensamente a comienzos de los noventa, en un sentimiento de quiebra de los equilibrios intergrupales. Sobre todo en un sentimiento compartido de amenaza y de agravio por el laissez faire en materia de las relaciones étnicas al que habría cedido el poder público, al tiempo que imponía a los vecindarios cuotas de inclusión y solidaridad étnica. Cuotas desigualmente repartidas entre los hábitats de distintas clases sociales, se denunciaba, así como limitantes de las oportunidades de integración y promoción de las mayorías precarizadas frente a los avances a lo largo del cuerpo social de la "pobreza desviada" que representarían las familias gitanas en los barrios. Eran estos, por tanto, discursos que giraban en torno a expectativas segregativas y sociales rotas por la multiplicación de planes de realojo de grupos estigmáticos solamente en lugares donde se seguían reclamando, en cambio, equipamientos sociales revitalizadores del entorno precarizado.

Junto al de las expectativas segregativas rotas, un más limitado (por las fuentes) análisis ${ }^{56}$ de las demandas y agravios vecinales reflejados (ahora en noticias de prensa) señaló también el peso en estos eventos antigitanos del discurso de los «dones incompletos», esto es, no correspondidos con esfuerzos de resocialización por parte de colectivos juzgados como invariables beneficiados por las administraciones de recursos escasos como viviendas y otras ayudas sin que, a cambio, manifestaran cambios de conducta justificativos de las preferencias obtenidas.

En este marco más amplio de tensión y conflictividad étnica se ubican también las revueltas frente a la incorporación de los gitanos a las escuelas.

\footnotetext{
Río (2014).

Leal (2002).

55 López y Fresnillo (1995): 86-88.

56 Río (2014): 51-53.
} 
Proceso que ha llegado a ser definido como «avalancha»... «En muchos colegios públicos aparecen por primera vez en esta época niños gitanos, y en otros se multiplica su número desde proporciones desdeñables hasta proporciones mucho más importantes ${ }^{57}$. Varios factores imbricados impulsan este proceso escolarizador.

En primer lugar, están las gitanas y gitanos diversos, aunque casi siempre invisibles frente al poder homogeneizador de los estereotipos. Una parte de la población gitana tradicionalmente alejada de la norma escolar diversificaba en estos años sus condiciones vitales y actitudes frente a la "escuela paya», especialmente a medida que los nichos económicos y fórmulas tradicionales de inserción laboral gitana desaparecían ${ }^{58}$.

En segundo lugar, en la incorporación escolar gitana influyó sobre todo la nueva panoplia de normas y de acciones administrativas conformadoras de una nueva estructura de oportunidades escolares para la minoría. Las primeras medidas de educación compensatoria en España de principios de los ochenta se establecieron pensando especialmente en la «integración» de "grupos» en "condiciones de inferioridad en el sistema educativo» como los gitanos $^{59}$. La nueva legislación inclusiva, aunque en construcción durante la primera mitad de los ochenta, estuvo acompañada de la suficiente acción administrativa para materializarla, eso sí, en colegios públicos. Lo relataba un padre: «Me acuerdo la primera vez que llevé cosas al Consejo Escolar [...]. Fue la primera vez que nos mandaron a tantos niños gitanos. Estuvimos hablando con el Concejal del Distrito y con el del Ministerio. Le dijimos que, bueno, que como representantes del APA del colegio nos negábamos en redondo. ¿Y sabes lo que nos contestaron? " Que era un plato de lentejas, que si querías las comieses" " ${ }^{60}$.

Parte importante de los menores gitanos cuya escolaridad iba a imponerse en centros públicos procedía de escuelas-puentes. Estos centros pasarán a la irregularidad tras promulgarse la Ley Orgánica del Derecho a la Educación

\footnotetext{
Fernández-Enguita (1999): 111.

San Román (1997).

59 El Real Decreto 1.1174/83 sobre Educación Compensatoria, del 27 de abril de 1983 (BOE de 11 de mayo), establece la «decidida voluntad de realizar una política compensadora de las de desigualdades sociales en materia educativa, buscando la integración de aquellos grupos cuyas condiciones de inferioridad en el sistema educativo, por su baja capacidad económica, su nivel social, lugar de residencia, etc., son manifiestamente acusadas en relación a las condiciones que el propio sistema educativo ofrece, con carácter general, a todos los alumnos y alumnas».

60 Entrevista en grupo, cit. en Fernández-Enguita (1999): 112.
} 
(LODE), en el verano de $1985^{61}$. El alumnado gitano en escuelas-puente de barriadas gitanas había ido aumentando años atrás, especialmente tras ser reconocidos tardíamente en 1978 estos centros creados por la iglesia-apostolado católico desde décadas antes. Se ha estimado que al llegar a mitad de los ochenta el momento de su desmoronamiento, las escuelas-puente absorbían al 83\% del alumnado gitano escolarizado ${ }^{62}$. En 1989, en cambio, el porcentaje de alumnado gitano escolarizado «en situaciones legales» era del $87 \%{ }^{63}$.

El desmantelamiento de las escuelas-puente se produjo en pocos años, pero no fue una demolición automática. Hubo acciones destacables que ofrecen un valioso contrapunto a los fenómenos discriminatorios reconstruidos. En Barcelona los propios maestros se unieron para reclamar el cierre de una escuela-puente tardíamente en funcionamiento ${ }^{64}$. No obstante, si muchas escuelas-puente aún seguían en funcionamiento irregular después de 1985, como veremos, ello se debía a las resistencias de los colegios y barrios cercanos a la hora de incorporar al alumnado gitano, como establecía la nueva legislación. Y como crecientemente exigían también unas asociaciones gitanas cada vez más activas y exigentes en la denuncia de la segregación educativa y del etnicismo escolar.

Varios casos dan cuenta de este creciente protagonismo del movimiento asociativo gitano como sujeto activo en la quiebra de la segregación educativa de la escuela pública. En junio de 1986 organizaciones gitanas denunciaban que en Burjassot (Valencia) los colegios negaban la admisión de 47 niños gitanos ${ }^{65}$. En enero de 1987 una asociación gitana de Torrent (Alicante) denunciaba otra "escuela puente ilegal» ${ }^{66}$. Este creciente activismo gitano por la desaparición de las escuelas-puentes contrasta con la escasa contestación a la segregación apenas unos años antes, como vimos en Burgos durante 1978.

El episodio más trascendente de lucha gitana contra la segregación educativa se localiza en Campanillas (Málaga). Una inicial acción gitana contra una escuela-puente está detrás de una de las resistencias antigitanas más contumaces de la democracia. En septiembre de 1988 una asociación gitana

61 Ley Orgánica 8/1985, de 3 de julio, reguladora del Derecho a la Educación (BOE 159/85 de 4 de julio de 1985).

62 Esteban (1989).

63 Vieira Ferreira (1999): 243.

64 «Maestros piden el cierre de un colegio instalado en un suburbio», El País, edición de Barcelona, 10-6-1986.

65 «Asociaciones gitanas denuncian que dos colegios públicos no admiten a 47 niños gitanos», El País, edición de Valencia, 10-6-1986.

66 «Una asociación gitana de Torrent denuncia una escuela puente ilegal«, El País, edición de Valencia, 10-1-1987. 
denunció en un primer momento una «escuela puente» aún funcionando en una estigmatizada «barriada de transición», Los Asperones, colindante a Campanillas. La denuncia gitana demostraba la pasividad de la Administración, que rehuía el conflicto social que la inclusión de los niños gitanos de Los Asperones desencadenaría en la colindante Campanillas. Frente a la inacción administrativa, los activistas gitanos de la «Asociación Sociocultural para el Desarrollo del Pueblo Gitano" aceleraron los acontecimientos. Primero convocaron a la prensa. Luego trasladaron en autobuses a los nińos gitanos de la escuela puente de Los Asperones al centro público de Campanillas. Finalmente, gracias a la movilización étnica recogida en la prensa local, la Administración educativa reaccionó. Se comprometió a la escolarización de los gitanos que hasta entonces postergaba ${ }^{67}$.

Hubo que esperar, sin embargo, hasta comienzos del curso siguiente, septiembre de 1989, para que llegaran al colegio de Campanillas los primeros niños de Los Asperones. Como preveían las autoridades, explotaron disturbios. Una vez más, durante varios días niños gitanos accedían a un colegio entre un cordón policial y cámaras de televisión. Las puertas fueron varios días bloqueadas con silicona. Hubo que intervenir para abortar enfrentamientos entre madres gitanas y no gitanas. Fue incendiada la sede del PSOE de Campanillas. Durante diez días la mayor parte del alumnado estuvo en huelga. Los niños gitanos menores que aún quedaban en la escuela gitana de Los Asperones también hicieron huelga, pero en solidaridad con sus compañeros rechazados en el cercano colegio de Campanillas que les correspondía, el Calderón Púa.

Pese a la tenacidad y cohesión demostrada, la protesta local cedió por la presión mediática nacional, sumada a la presión judicial de empezar a multar a quienes no llevaran a los niños a clase. En Campanillas, en uno de los más importantes conflictos escolares de la España democrática, el activismo gitano desarrolló en origen un papel clave. Con su acción comprometió a la Administración acelerando la inclusión escolar de la población gitana ${ }^{68}$. Tras el caso de Campanillas nuevos editoriales en la prensa española denunciaban el racismo escolar exigiendo avances en el derecho a la educación de los gitanos ${ }^{69}$. Bajo multitudinarias resistencias civiles, el derecho a la igualdad de acceso escolar de la infancia gitana seguía avanzando.

67 «Educación se compromete esta semana a escolarizar a los treinta niños de una barriada de transición», Diario Sur, Málaga, 20-9-1988.

68 «Paralizado un colegio de Málaga para impedir que asistan a clases 14 niños de un poblado marginal», El Pais, 5-10-1989, p. 27.

69 «Niños gitanos sin escuela (sesión continua)», El Sol, 29-9-1989. 
Como se apuntaba, junto al nuevo marco legal para la inclusión educativa, el factor más determinante de aquellas protestas escolares fue la multiplicación en estos años de los programas de realojamiento de población gitana. Los realojos y los «censos» previos a estos aumentaron la responsabilidad y a la vez el grado de control de las distintas administraciones con respecto a la escolaridad gitana. Estas debían ahora proporcionar el derecho a la educación a decenas de miles de menores realojados procedentes de hogares cuyas obligaciones escolares aparecían a la vez mucho más objetivadas y controladas que en los anteriores hábitats. La mayor parte de los menores rechazados en estos años pertenecían a familias gitanas objeto de operaciones de realojo que, según se señalaba ya en 1986, «habían erradicado gran parte del chabolismo existente, incorporando un volumen importante de gitanos a núcleos de población no gitana» ${ }^{70}$.

Las tensiones vecinales desencadenadas por el traslado de poblaciones procedentes de núcleos estigmatizados frecuentemente se trasladaron a las escuelas. Muchas veces el estallido vecinal, en vez de relacionado con el volumen de estudiantes gitanos que llegaban, se enmarcaba en tensiones en los barrios más cercanos a los realojos. En Andújar, todavía en 1990, quedaban trescientos menores gitanos por escolarizar. El reparto entre los distintos centros de una localidad con más de cuarenta mil habitantes, reconocían las autoridades, estaba generando tensiones en los distintos colegios. Sin embargo, siendo ubicuas las tensiones en todos los centros previstos para albergar alumnado gitano, el conflicto abierto estalló en el centro más cercano a la barriada gitana de la localidad ${ }^{71}$.

Otro conflicto similar se produjo, durante el otońo de 1991, en el madrileño barrio obrero de Villaverde. En solo una mañana «treinta» madres reclutaron a muchas más para cerrar un colegio al que asistían veinte nińos gitanos entre otros quinientos cincuenta alumnos. La acción vecinal citada se inscribía, en cambio, en las masivas protestas de aquellos mismos días contra la «venta de droga» y contra la instalación en un solar del barrio de familias gitanas procedentes del poblado chabolista de Torregrosa:

Tocan las palmas en clase, bailan encima de las mesas y no le hacen caso a la señorita, con lo cual ni aprenden ni dejan aprender a los nuestros". Ésa era una de las razones que alegaron ayer las madres [...]. Al final no entraron ni los suyos ni los otros, porque lograron convencer a los demás padres [...]. Algunas

70 Garrido y Torres (1986): 135.

71 «Los alumnos de un colegio de Andújar siguen sin ir a clase por asistir cinco niños conflictivos», El País, 20-11-1990, p. 3. 
madres se quejaban de que los nińos gitanos introducen drogas en las clases y acostumbran a propinar palizas a sus vástagos [...]. De los 550 alumnos matriculados, 20 son gitanos integrados en el pueblo y 80 proceden de las casas prefabricadas del barrio de Torregrosa, pero de estos últimos sólo 40 asisten con cierta regularidad [...]. La razón que ocasionó el piquete de la mañana fueron las becas de comedor del colegio. «Este año había mucha gente y hemos tenido que retirar a unos $40^{72}$.

El conflicto escolar de Villaverde se cita también porque reúne en un mismo caso las distintas motivaciones y demandas que, en distintos momentos del repertorio de protestas escolares, se irán desplegando contra la presencia gitana en las escuelas. Las motivaciones del rechazo a la presencia gitana experimentaron modulaciones. En un primer momento, cuando la Administración impone la presencia gitana en aulas hasta entonces monoétnicas, al nuevo alumnado se le acusará sobre todo de representar riesgos y malas influencias, ocupando el miedo a la "violencia» un papel destacado ${ }^{73}$. Posteriormente, a medida que crece la ilegitimidad del rechazo a menores y se consolida la legitimidad de la presencia gitana en las aulas, las motivaciones y reivindicaciones vecinales se diversificarán y complejizarán. Progresivamente se señalarán, como ocurrió en Villaverde, las preferencias y mal uso de las ayudas escolares por parte de familias gitanas. Sobre todo se incidirá en los perjuicios que para el avance educativo del alumnado no gitano representa la coexistencia, sin más medios en los centros, con un alumnado que arrastraría masivamente dificultades escolares.

Otro importante episodio de etnicismo escolar, de nuevo ubicable en el rechazo a proyectos de realojo, fue el de Tremañes (Gijón, 1985). Un año antes el vecindario ya se había movilizado masivamente, aunque sin éxito, contra la construcción de viviendas para familias gitanas. Los niños de las familias realojadas formarían parte también del nuevo colegio que se construía en la zona. La confirmación oficial de la escolarización temida desató entre enero y marzo de 1985 nuevas protestas, combinadas con amenazas de boicot popular al nuevo colegio ${ }^{74}$. Meses después del fracaso cosechado por los antigitanos en Vicálvaro, la nueva firmeza de las autoridades convirtió en estériles las movilizaciones. Fracasada la resistencia contra la

\footnotetext{
72 «Treinta padres cierran un colegios que acoge a gitanos», El País, edición de Madrid, 9-3-1991.

73 Fernández-Enguita (1999).

74 «Padres de alumnos de un colegio gijonés se oponen a la entrada de niños portugueses», El País, 11-1-1985, p. 16
} 
presencia gitana en las aulas, los manifestantes modularon sus reivindicaciones. Del rechazo a la presencia pasaron a pretender la dispersión de los gitanos entre centros y el diseño de llamativas medidas de segregación intraescolar:

No estamos contra la integración, como se ha dicho. Lo que pedimos es que no sea masiva. Si quieren escolarizar a todos estos nińos que los repartan entre todos los colegios que existen en Gijón. Jesús Gómez, miembro de la comisión gestora establecida por los padres, rechaza también la posibilidad de que coman juntos, en un mismo comedor, nuestros hijos con estos otros nińos aquejados de enfermedades, suciedad y falta de práctica en la convivencia social» [...]. Anuncian que mantendrán a sus hijos en el actual centro, aunque sea sin profesores, si siguen sin escucharse ninguna de sus pretensiones ${ }^{75}$.

En todos estos y otros muchos casos, los estigmas acumulados por los lugares de procedencia de los menores gitanos tuvieron un papel crítico en las protestas escolares. No obstante, el abanico de posibilidades de acciones antigitanas en las escuelas es más amplio. Hubo boicots escolares, entre ellos el citado de Mancha Real, que se enmarcaron en estrategias etnicistas de más amplio alcance, como evitar el asentamiento o conseguir la expulsión de familias gitanas instaladas en las localidades. En 1987, los padres de ochocientos niños de un colegio en una barriada onubense declararon una huelga para expulsar a una familia gitana ${ }^{76}$. Dos años antes, en Sagonera (Murcia), lo que se buscaba era impedir la instalación de una familia gitana, «nueve personas». «Mil niños» de «tres colegios» fueron utilizados por sus padres ${ }^{77}$.

\section{LA CONSOLIDACIÓN DE LA PRESENCIA GITANA EN LAS ESCUELAS ESTATALES}

Entre 1976 y 1995 solo el diario El País reportó 213 casos de acción colectiva antigitana en España ${ }^{78}$. Sin embargo, a lo largo de esas dos décadas

75 «Vecinos de un barrio de Gijón se oponen a que sus hijos compartan aulas con los gitanos», El Pais, 5-3-1985, p. 20

76 "Huelga de ochocientos escolares para que expulsen de Huelva a una familia gitana», Diario 16, Andalucía, 24-10-1987.

77 «Paro escolar por la llegada de una familia gitana», El Pais, 10-12-1985, p. 19.

78 Para la contabilización de los casos de acción colectiva antigitana entre 1976 y 1995 se han revisado, previa delimitación precisa de las unidades de análisis buscadas, los 
este medio únicamente dedicó cinco editoriales a este tipo de conflictos socia$\operatorname{les}^{79}$. Pese a la escasez de editoriales, el papel de los medios de comunicación en los procesos de reflexividad y de litigación supralocal que desencadenarán los conflictos antigitanos resultará cada vez más decisivo.

El tratamiento periodístico de los conflictos escolares fue además el que más tendió a enfatizar la «motivación racista» de los manifestantes. Y el que más tendió, al estallar los casos, a exigir medidas de las autoridades que, primero, abortasen la discriminación producida en un lugar y, segundo, hiciesen avanzar los derechos postergados de la infancia gitana en otros lugares. Como se anotaba, el tercero de los cinco editoriales de El País a raíz de conflictos antigitanos, el 9 de enero de 1985, denunciaba «el racismo» desatado en el citado colegio Severo Ochoa de Vicálvaro. Exigía firmeza democrática a las autoridades. Concluía pidiendo avances decididos frente al racismo histórico y la injustificada postergación de la cuestión escolar gitana. Criticaba también a la autoridad del colegio por intentar neutralizar en un primer momento el conflicto reservando un aula separada a los gitanos. Señalaba por último a Vicálvaro como "lugar de una vergüenza que todos debemos asumir como colectiva» ${ }^{80}$. El titular del editorial evocaba los sucesos de Little Rock, un conflicto racial de 1957 en una escuela federal norteamericana posteriormente cinematografiado. Informe Semanal de TVE también dedicó uno de sus reportajes al conflicto el segundo sábado de enero de 1985. Justo la semana en que los niños gitanos, pese a la existencia de cámaras y periodistas en el centro, habían tenido que entrar a clase escoltados por la policía ${ }^{81}$.

Este conflicto aceleró el cuestionamiento social (y la posterior eliminación) de las escuelas-puente que prevalecían en Madrid y otras grandes ciudades españolas a primeros de los ochenta. Tras Vicálvaro, la Dirección Provincial

índices de El País. Estos incluían fecha y titular de la noticia más localización de la misma en las distintas secciones del periódico.

79 El primer editorial fue a raíz de la expulsión de los gitanos de Hernani en enero de 1980. La segunda, tras los enfrentamientos entre gitanos y no gitanos en el madrileño barrio de San Cristóbal, también en enero de 1980. El tercer editorial llegó tras el conflicto escolar de Vicálvaro en enero de 1985. Los dos últimos editoriales llegan tras la expulsión de los gitanos de Martos en julio de 1986 y de Mancha Real en mayo de 1991.

80 «Little Vicálvaro”. El Pais, Op., 9-1-1985.

81 La notable relevancia mediática de los sucesos de Vicálvaro, tanto para la prensa como para la televisión nacional, puede también valorarse teniendo en cuenta la ausencia de reportajes y de editoriales tras los sucesos de Torredonjimeno que analizó Río (2003). En este pueblo jiennense, justo un año antes, resultaron quemados varios niños tras incendiar una multitud la vivienda que ocupaban. 
de Educación de Madrid desarrolló un programa con el objetivo de escolarizar a los aproximadamente tres mil nińos gitanos que aún no tenía educación asegurada en la Comunidad de Madrid. A principios del curso siguiente «se matricularon 1.132 alumnos gitanos distribuidos en 55 colegios» ${ }^{82}$.

En las reacciones supralocales (mediáticas e institucionales) frente a episodios posteriores, pero similares a los de Vicálvaro, concurrirán regularmente una serie de elementos mucho menos estructurados hasta antes de este trascendente caso. Por un lado, el tratamiento mediático de los sucesos de Vicálvaro estructuró las reacciones posteriores de toda la prensa ante nuevos casos. A diferencia de lo que sucedía en la Transición, los protagonistas de episodios de antigitanismo escolar, tras Vicálvaro, pasarán a ser frecuentemente representados como encarnaciones del más injusto de los racismos, el focalizado en niños. Esto introduce una diferencia notable de tratamiento mediático entre protestas escolares y protestas contra realojos. En las últimas la prensa se mostraba generalmente más ambivalente a la hora de atribuir motivaciones etnicistas a los participantes. De hecho, la catalogación más habitual de las protestas contra realojos era la de «conflicto vecinal». Resultaba en estos casos menos frecuente la atribución de «racismo» a los manifestantes ${ }^{83}$.

El modo en que la propia prensa progresista de la época relató casos ya citados, como el de la construcción de una «escuela gitana» en Burgos durante 1978, ilustra la escasa denuncia durante la transición de fórmulas segregativas. Y esto a pesar de que en estos años aumentó la concentración de alumnado gitano escolarizado en escuelas-puente ${ }^{84}$. En cambio, tras los acontecimientos de Vicálvaro, se intensificarán en los periódicos las descripciones críticas de las condiciones de postergación escolar de las que procedían los menores que eran rechazados en las nuevas escuelas. Vicálvaro inaugura también la unidad de acción entre autoridades locales y no locales ante casos de etnicismo escolar. Unidad política en cambio escasa en conflictos contra proyectos de realojamiento ${ }^{85}$.

La derrota de los manifestantes antigitanos de Vicálvaro fue clave en las otras que posteriormente experimentaron, ya en otros puntos del país meses y años después, quienes sin eficacia también recurrieron a la acción colectiva para intentar excluir al alumnado gitano de escuelas públicas, en lugar de a estrategias personales de exclusión étnica más caras pero legalizadas, como

\footnotetext{
82 «Educación inicia la escolarización de 3.000 niños calés», El País, edición de Madrid, 5-2-1986, p. 22.

83 López y Fresnillo (1995).

84 Vieira Ferreira (1999).

85 Río (2014).
} 
ocurre con las fugas a colegios concertados sin gitanos. También a raíz del conflicto de Vicálvaro se han localizado las primeras evidencias documentales del debate, incipiente entonces, sobre la exclusión de la infancia gitana de las escuelas concertadas españolas. El siguiente documento revela cómo el caso de Vicálvaro influirá en dinamizar los planes de la nueva Administración educativa socialista para las escuelas concertadas. Después de los sucesos madrileños, y de otros meses después como los del barrio gijonés de Tremañes, medios de comunicación y responsables educativos comenzaban a plantear la necesidad de un avance más: imponer y lograr la inclusión gitana en centros concertados sostenidos con fondos públicos:

La integración escolar de los niños de raza gitana, tarea en la que el Ministerio de Educación afirma sentirse comprometida desde antes de que los últimos incidentes de Madrid [caso Severo Ochoa] y Gijón [caso Tremañes] actualizasen el problema de la discriminación escolar de este sector, va a ser en un futuro no muy lejano competencia no sólo de los centros públicos, sino también de los colegios privados subvencionados por el Estado, entre los cuales no abundan las iniciativas de este tipo [...]. El plan de integración educativa, después de aplicarse a los colegios públicos, desde donde hace años se admiten matriculas de gitanos, se extenderá a otros centros que tendrán que abrir sus puertas por primera vez a una clientela tradicionalmente ajena a sus instalaciones ${ }^{86}$.

Aquellos planes apenas se materializaron, sin embargo. Hasta 1993 no se dictaron medidas específicas que obligaban a «la redistribución equilibrada de niños pertenecientes a grupos sociales y culturales desfavorecidos entre centros sostenidos con fondos públicos, evitando su concentración excesiva» ${ }^{87}$. Revisando la prensa hay que esperar hasta mitad de los noventa para encontrar algún caso como el de Palencia, donde ocho centros religiosos fueron multados porque rechazaban las órdenes de la autoridad educativa provincial de escolarizar a menores gitanos ${ }^{88}$.

El caso más importante de conflicto étnico en un concertado fue, no obstante, el del San Juan Bosco de Barakaldo, aunque tuvo lugar en

86 «Programa oficial para favorecer la integración escolar de los gitanos», El Pais, 16-4-1986.

87 Real Decreto 277/1993 y Real Decreto de 28 de febrero 299/1996 (BOE núm. 62, de 12 de marzo de 1996) de «ordenación de las acciones dirigidas a la compensación de desigualdades en la educación».

88 «Ocho colegios religiosos de Palencia se niega a acoger a niños gitano», El País, 23-71996, p. 26. 
noviembre de 2000. Aquí la Delegación de Educación impuso también a la dirección del centro religioso la presencia de menores gitanos, pero fueron entonces los padres quienes se movilizaron convocando una huelga escolar. La coacción ejercida por los anuncios de actuación de la Fiscalía terminó aquí también con las protestas ${ }^{89}$.

A medida que crecían la ilegitimidad y el coste social de oponerse a la presencia de alumnado gitano, se extendían los agravios por el desigual reparto del alumnado gitano entre centros. Desigualdad muy marcada entre centros públicos y concertados. Al comenzar el curso de 1991, en Aitona (Lérida) las familias del colegio público local se admitían dispuestas a la escolarización de una parte de los niños de familias gitanas recién empadronadas. Mantuvieron, en cambio, una huelga escolar hasta que la Administración impuso al centro concertado del municipio la acogida de la mitad de los nuevos alumnos ${ }^{90}$.

A pesar de la extendida exclusión de la infancia gitana de centros concertados, a finales de los noventa Espańa era valorada «entre los países europeos con un modelo de escolarización gitana más integrador ${ }^{91}$, al menos en términos de acceso. Remontados los convulsos años ochenta, las propias asociaciones gitanas recordaban las dificultades del pasado reciente y los éxitos conseguidos en la lucha contra la discriminación escolar:

El conflicto del colegio Ruiz Gordoa de Andújar [...] nos trae a la memoria sucesos que ocurrían con mucha frecuencia en los inicios de los ochenta, tales como los de Vicálvaro, San Blas, etc. Afortunadamente estos hechos se producen ya muy de cuando en cuando, y tanto padres de alumnos como profesores, han ido asumiendo que los nińos gitanos tienen que incorporarse a la escuela como el resto de los espańoles. La fase por tanto de la incorporación masiva de los niños gitanos a la Enseñanza General Básica está siendo completada. Entramos en otra etapa en la que nos preocupa son los resultados ${ }^{92}$.

La «incorporación masiva» de la infancia gitana a las escuelas estatales terminó extendiendo, no obstante, nuevas respuestas y estrategias de exclusión. En las noventa se extienden las "fugas» — whyte flight- hacia colegios sin gitanos. A veces estos procesos de exclusión generalmente encubierta han

\footnotetext{
89 «Barakaldo, una herida cicatrizada», El Pais, 18-11-2000.

90 «Los dos colegios de Aitona niegan la entrada a gitanos», El Observador, Barcelona, 21-09-1991.

91 Etxebarría (2000): 173.

92 «Editorial», boletín Gitanos en la prensa, Secretariado General Gitano, 1990, p. 2.
} 
sido tan llamativos que se han convertido en noticia. Fue el caso de Valladolid. En 1989 «cuarenta» familias no gitanas concertaron dar de baja a sus hijos para el siguiente curso. Sospechaban que serían más quienes lo hicieran. Los padres movilizados denunciaban las condiciones en que se estaba produciendo la incorporación del alumnado gitano. La fuga se decidió una vez fracasaron las exigencias de reparto del alumnado gitano entre centros y de agrupación por niveles del alumnado:

Cuarenta padres payos han dado de baja a sus hijos del colegio Pío del Río Orcega durante las últimas semanas como consecuencia del bajo nivel educativo al que obliga la presencia de un alto porcentaje de alumnos de etnia gitana. [...]. Creen que finalmente abandonarán el centro unos ciento veinte niños, pues muchos de ellos no han presentado la baja aún, pero tienen solicitada plaza en otro centro [...]. Han planteado con insistencia al Ministerio de Educación la necesidad de actuar redistribuyendo a la población gitana del colegio entre otros colegios, u homogeneizando las clases por niveles educativos [...]. Las asociaciones gitanas han mostrado también su oposición a las propuestas payas ${ }^{93}$.

Ha venido desde hace años denunciando también estas situaciones, pero ha sido escasa la capacidad del movimiento asociativo gitano para frenar los poderosos mecanismos de segregación intraescolar e interescolar que se dan en la Espańa de la doble red educativa. La reproducción intergeneracional del fracaso escolar entre las distintas generaciones gitanas escolarizadas en las últimas décadas requiere, sin embargo, tomar medidas para diversificar la presencia gitana a lo largo de todo el mapa escolar. Esa es otra asignatura pendiente para el futuro de nuestra convivencia étnica.

\section{CONCLUSIONES}

Masiva desescolarización en el franquismo en coexistencia con prácticas de discriminación institucional. Aumento a partir de los setenta de la escolarización, pero prevaleciendo la segregación educativa bajo el modelo de escuelas-puente que rara vez atravesaban los menores gitanos. Estos dos hechos definieron las condiciones escolares de la infancia gitana hasta los ochenta.

En esos años, en cambio, se producirá una incorporación sin precedentes de menores gitanos a escuelas estatales. La normativa que se construyó y

93 "Cuarenta padres han dado de baja a sus hijos en el colegio del Río Orcega», El Norte de Castilla, 22-7-1989. 
empezó a aplicar aquellos años hubiera permitido a los poderes públicos imponer proyectos de inclusión y normalización educativa de mayor alcance interclasista. En la práctica, sin embargo, la nueva presencia de escolares gitanos quedó muy limitada a centros públicos de barriadas obreras. Lugares donde se efectuaban también en estos años proyectos de realojamiento de familias gitanas. Grupos que, extraídos la mayoría de las veces de asentamientos estigmatizados y estigmáticos, concitaban intensos rechazos y movilizaciones vecinales. La conflictividad étnica en los barrios se trasladó frecuentemente a sus escuelas. En muchas de ellas la presencia de alumnado gitano pasará, en pocos años, de proporciones desdeñables a proporciones significativas.

En las revueltas escolares contra este nuevo alumnado se materializaron distintas tácticas de presión y boicot popular cuyo grado de disrupción e ilegitimidad social varía. Algunos casos supusieron protestas difusoras de los perjuicios y prejuicios asociados a la presencia de escolares gitanos, como el de la bajada de nivel del resto del alumnado o el de la violencia ejercida como tarjeta de presentación en sociedad también por parte de los menores. Otros casos, en cambio, salieron a la luz pública porque traspasaban el escalón de la protesta y se transformaban en acciones directas de boicot al alumnado gitano. La táctica de presión más recurrente fue, no obstante, la huelga escolar.

La historia de estas revueltas es la de un ciclo de conflicto étnico donde los vecindarios consecutivamente implicados irán cosechando cada vez más predecibles, poderosas y sostenidas reacciones contrarias. La frecuencia en la prensa de este tipo de casos, habituales en los ochenta, descendía a medida que avanzan los noventa. A medida también que se imponían y extendían otras estrategias más individualizadas de exclusión, como la «fuga» a colegios sin gitanos.

$\mathrm{Al}$ poner de manifiesto la intransigencia de mayorías adultas, concertadas para negar derechos fundamentales a menores, estos conflictos contribuyeron paradójicamente a crear estados de opinión pública y estructuras de oportunidades políticas que aceleraron y consolidaron medidas contra la histórica marginación escolar de la población gitana. La creciente legitimidad de la presencia gitana en las escuelas públicas fue en parte construida durante las litigaciones en las que desembocaban los conflictos.

El papel que cupo a los propios gitanos en estas batallas contra el etnicismo desatado en las escuelas estatales quizás no esté suficientemente resuelto en este texto. A diferencia de otros países con otras comunidades racializadas ${ }^{94}$, en España hasta ahora no se había siquiera planteado (en espacios académicos) qué papel ha podido jugar el activismo y movimiento asociativo gitano en el avance de los derechos de esta población, también ante la escuela. Domina por el

94 Olzak (1992) y McAdam (1999). 
contrario una imagen muy crítica de los condicionantes de este movimiento para constituirse en sujeto político. Prevalece la visión arcaizante de que los gitanos solo se organizarían bajo el peso de solidaridades clánicas-adcriptivas que impedirían el germinar de una conciencia étnica moderna. Importantes fenómenos de movilización estatal étnica, como el desatado en 1976 tras estrenarse la obra Camelamos naquerar, dedicada a la persecución gitana, no han concitado preocupación académica hasta fechas muy recientes ${ }^{95}$. Se ha minusvalorado también que la primera manifestación gitana, el 6 de junio de 1978 en Puerta del Sol, precipitó la abolición semanas después de los ya citados artículos discriminatorios en reglamentos policiales. Y que la segunda manifestación reivindicativa, el 16 de julio de 1986, se celebró también en Madrid a raíz del incendio de un barrio gitano en Andalucía, surgiendo meses después una publicación étnica aún en vigor como Nevipens Romaní.

Frente a todo esto, y aunque es una conclusión provisional que exigirá de más exhaustivos análisis futuros, este artículo reconstruye situaciones indicativas de cómo a medida que transcurre la democracia, pero continúan en cambio reproduciéndose episodios de antigitansimo, irá multiplicándose la capacidad denunciante y litigante de las asociaciones gitanas frente a episodios de discriminación escolar. De apenas cuestionar en los setenta el modelo de escuelas segregadas, hemos visto, las asociaciones gitanas pasarán progresivamente a la denuncia de este tipo de colegios desde mediados de los ochenta. A su vez, frente a los casos de etnicismo en las escuelas, las asociaciones gitanas resultarán actores cada vez más activos e influyentes a la hora de imponer — ante medios de comunicación y distintos representantes de los poderes públicos como gestores escolares y funcionarios de justicia- marcos interpretativos sobre la desigualdad de trato y el racismo experimentado históricamente por el pueblo gitano, el cual se materializaría de la manera más injusta, escandalosa y denunciable precisamente en el boicot vecinal a menores gitanos privados de la socialización interétnica en las aulas y del derecho a educarse de manera igualitaria. La reacción de las asociaciones gitanas tras el episodio de discriminación escolar de Mancha Real, donde se dictarán pioneras sentencias por discriminación escolar, representa un botón de muestra en este sentido.

En un plano teórico más general, el artículo sugiere el papel clave del Estado en el curso de las relaciones interétnicas. La exclusión colectiva que se emprende contra minorías, como la población gitana, vendría facilitada por

95 La tesis reciente de Quintanilla (2016) analizaba el impacto mediático de esta obra clave de la memoria gitana. Su estreno en diferentes ciudades trató de boicotearse, entre otros, por el Partido Racial Democrático, cuyo objetivo era expulsar de España a los gitanos. 
determinadas políticas segregativas vigentes en el pasado que conforman expectativas segregativas de la población civil mayoritaria en ámbitos como la escuela. En el mismo sentido, este trabajo robustece la tesis de que los sistemas de desigualdad y dominación étnica sometidos a procesos desegregativos experimentan una intensificación de las divisorias, antagonismos y conflictos étnicos.

Por último dos consideraciones. Primera: la conciencia crítica emanada del conocimiento histórico del antigitanismo no basta para contribuir desde las ciencias sociales a mejorar la imagen de la población gitana y la convivencia étnica ${ }^{96}$. Necesitamos también difundir historias en común y casos de convivencia fluida y de solidaridad interétnica, en el pasado y en el presente. La ausencia de información sobre esas otras situaciones, contrapunto de las discriminatorias aquí abordadas, constituye quizás otra de las limitaciones de este artículo.

Segunda: la necesaria investigación y memoria histórica del antigitanismo, a la cual puede contribuir este artículo, debe también dar cuenta de los frágiles y lentos avances registrados en las últimas décadas frente al racismo y la desigualdad de trato hacia la comunidad gitana. En ese sentido, este análisis revela que las situaciones de protesta social y conflictividad etnicista eran menos frecuentes cuando, en cambio, la distribución interétnica de derechos y oportunidades sociales (como las educativas) resultaba mucho más injusta para la población gitana española.

\section{Bibliografía}

Abajo, J. (2010). El padre Manjón y la escolarización de la infancia gitana. I Tchatchipen, $72,27-35$.

Archer, M. (1979). Social Origins of Educational Systems. London and Beverly Hills: Sage.

Díez, J. (1994). Aplicación de los modelos de competición y segregación al estudio del nacionalismo vasco. Cuadernos, 26, 11-23.

Esteban, T. (1989). Evaluación de la escolarización de los niños gitanos y expectativas de futuro. En Primeras jornadas Estatales de seguimiento Escolar con minorias étnicas. Astorga: Asociación Secretariado General Gitano.

Etxebarría, F. (2000). Políticas educativas en la Unión Europea. Barcelona: Ariel.

Fernández-Enguita, M. (1990). La cara oculta de la escuela. Educación y trabajo en el capitalismo. Madrid: Siglo XXI.

Fernández-Enguita, M. (1999). Niños gitanos en la escuela paya. Un estudio sobre relaciones interétnicas en el sistema educativo. Barcelona: Ariel.

96 Sierra (2018) ha apuntado una agenda de nuevas formas de hacer historia de los gitanos que podría servir para que la disciplina y las otras ciencias sociales ayuden a desnaturalizar estereotipos, en lugar de a naturalizarlos como muchas veces ha sucedido y sucede. 
Franzosi, R. (1987). The Press as a Source of Sociohistorical Data: Issues in Methodology of Data Collection from Newspapers. Historical Methods, 20 (1), 5-14. Disponible en: https://doi.org/10.1080/01615440.1987.10594173.

Garrido, M. y Torres, J. (1986). El problema de la educación gitana. En T. San Román (comp.) Entre la marginación y el racismo. Reflexiones sobre la vida de los gitanos (pp. 129-140). Madrid: Alianza.

Gómez-Alfaro, A. (1991). La reducción de los niños gitanos. Historia de la educación: revista interuniversitaria, 10, 187-202.

- (2009). Legislación histórica española dedicada a los gitanos. Sevilla: Consejería de Igualdad y Bienestar Social.

Gómez-Urdáñez, J. L (2015). El comienzo de la integración de los gitanos en Cataluña. Anatomía de la Historia. Disponible en: https://bit.ly/2NvYN14.

— (2017). Las medidas sobre los gitanos en el reinado de Carlos III: ¿De la extinción a la asimilación? Andalucía en la Historia, 55, 16-17.

Instituto de Sociología Aplicada (1982). El libro blanco de los gitanos españoles. Madrid: Secretariado Nacional Gitano.

- (1990). Estudio sociológico. Los gitanos españoles 1978. Madrid: Secretariado General Gitano.

Leal, J. (2002). Segregación social y mercados de vivienda en las grandes ciudades. Revista española de sociología, 2, 59-76.

Leblon, B. (1993) Los gitanos de España. Barcelona: Gedisa.

Lieske J. A. (1978). Group Disorders in Urban Schools. The Effects of Racial Desegregation and Social Emancipation. Urban Affairs Quaterly, 14, 79-101. Disponible en: https:// doi.org/10.1177/107808747801400104.

López, M. L. y Fresnillo, J. L. (1995). Margen y periferia. Representaciones ideológicas de los conflictos urbanos entre payos y gitanos. Madrid: Secretariado General Gitano.

Manjón, A. (1948). Lo que son las escuelas del Ave María. Modos de enseñar. En A. Manjón. Obras selectas, vol. 5 (pp. 6-31). Alcalá de Henares: Imprenta talleres penitenciarios de Alcalá de Henares.

McAdam, D. (1999). Marcos interpretativos y tácticas utilizadas por los movimientos: dramaturgia estratégica en el movimiento americano Pro-Derechos Civiles. En D. McAdam, J.D. McCarthy y M.N. Zald. Movimientos Sociales. Perspectivas Comparadas (pp. 475-495). Madrid: Istmo,

Nagel, J. (1995). Resource Competition Theories. American Behavioral Science, 38 (3), $442-$ 458. Disponible en: https://doi.org/10.1177/0002764295038003006.

— y Olzak, S. (1997) Movilización étnica en los nuevos y en los viejos estados. Una ampliación del modelo de competición. Zona Abierta, 79, 5-39.

Nielsen, F. (1985): Toward a Theory of Ethnic Solidarity in Modern Societies, American Sociological Review, 50 (2), 133-149. Disponible en: https://doi.org/10.2307/2095405.

Olzak, S. (1989). Analysis of Events in the Study of Collective Action. Annual Review of Sociology, 15, 119-141. Disponible en: https://doi.org/10.1146/annurev.so.15.080189.001003.

Olzak, S. (1992). The Dynamics of Ethnic Competition and Conflict. Stanford: Stanford University Press. 
—- Shanahan, S. y West, E. (1994). School Desegregation, Interracial Exposure and Antibusing Activity in Contemporary Urban American. American Journal of Sociology, 100 (1), 196-214. Disponible en: https://doi.org/10.1086/230503.

— y McEneaney, E. (1996). Poverty, Segregation and Race Riots: 1960 to 1993. American Sociological Review, 61 (4), 590-613. Disponible en: https://doi.org/10.2307/2096395.

- y Shanahan, S. (2003). Racial Policy and Racial Conflict in the Urban United States, 1869-1924. Social Forces, 82 (2), 481-517. Disponible en: https://doi.org/10.1353/ sof.2004.0019.

Parkin, F. (1984). Marxismo y teoría de clases. Una critica burguesa. Barcelona: Espasa.

Pérez, V. y Sánchez, P. (eds.) (2009). Memoria ciudadana y movimiento vecinal. Madrid, 1968-2008. Madrid: Los Libros de la Catarata.

Quintanilla, J. (2016). Impacto mediático de Camelamos naquerar en la prensa de la transición democrática [tesis doctoral]. Universidad de Sevilla. Disponible en: https://idus.us.es/ xmlui/handle/11441/33764.

Río, M. A. (2002). Visiones de la etnicidad. Revista Española de Investigaciones Sociológicas, 98 (2), 79-106.

(2003). Violencia étnica y destierro. Dinámicas de cuatro disturbios antigitanos en Andalucía. Granada: Maristán.

- (2008). Usos y abusos de la prensa como fuente de datos sobre acciones colectivas. Empiria. Revista de Metodología de las Ciencias Sociales, 16, 59-84. Disponible en: https://doi.org/10.5944/empiria.16.2008.1390.

- (2014). Políticas de realojo, comunidad gitana y conflictos urbanos en Espańa. 19802000. Quid 16: Revista del Área de Estudios Urbanos del Instituto Gino Germani, 16, 34-61.

- (2017). Los poderes públicos y los asentamientos de gitanos: siglos XV a XviII. Andalucía en la Historia, 55, 8-11.

Roosens, E. (1989): Creating Etnicity. The Process of Ethnogenesis. California: Sage

Salinas, J. (2009). Un viaje a través de la historia de la escolarización de gitanas y gitanos españoles. Anales de Historia Contemporánea, 25, 167-188.

San Román, T. (1980). La Celsa y la escuela del barrio. En M. Knipmeyer, M. González Bueno y T. San Román. Escuelas, pueblos y barrios. Tres ensayos de antropología educativa (pp. 163-263). Madrid: Akal.

- (1997). La diferencia inquietante. Viejas y nuevas estrategias culturales de los gitanos. Madrid: Siglo XXI.

Sierra, M. (2018). Historia gitana: enfrentarse a la maldición de George Borrow. Ayer, 109 (1), 351-365.

Vázquez-García, F. (2009). La invención del racismo. Nacimiento de la biopolitica en España, 1600-1940. Madrid: Akal.

Vieira Ferreira, M. (1999). La desigualdad en el proceso de escolarización de la infancia gitana en España. Revista de Educación, 319, 239-252.

Wilkes, R. y Okamoto, D. (2002). Ethnic Competition and Mobilization by Minorities at Risk. Nationalism and Ethnic Politics, 8 (3), 1-23. Disponible en: https://oi. org/10.1080/13537110208428667. 